Revista de Derecho YACHAQ

ISSN: 1817-597x (impresa) / ISSN: 2707-1197 (en linea)

Centro de Investigación de los Estudiantes de Derecho (CIED)

Universidad Nacional de San Antonio Abad del Cusco

N. ${ }^{\circ} 10-2019$

[pp. 47-62]

Fecha de recepción: 11/08/19

Fecha de aceptación:14/09/19

\title{
Panorama actual del arbitraje en contrataciones con el Estado: algunas reflexiones a propósito de las últimas modificaciones a la Ley $\mathrm{N} .{ }^{\circ} 30225$ y su reglamento
}

\author{
Current Overview of Arbitration in Contracting with The State: \\ Some Reflections Due to the Latest Modifications to \\ Law N. 30225 and its Regulation
}

\author{
Diego Fernando García Vizcarra ${ }^{[*]}$
}

\begin{abstract}
RESUMEN: la importancia de las contrataciones con el Estado ha dado lugar, en los últimos veinte años, al desarrollo de un marco regulatorio cada vez más amplio y especializado, en el cual la figura del arbitraje ha cobrado un protagonismo singular, dado que el propio ordenamiento peruano abstrajo de este mecanismo de solución de controversias sus características originarias, dotándole una identidad propia en este ámbito de aplicación.

Con los diversos cambios normativos que ha sufrido el régimen, el arbitraje en contrataciones con el Estado ha sido objeto de numerosos ajustes, tanto en lo sustantivo como en lo adjetivo, encontrándonos hoy en día ante una disciplina especializada que aún está en proceso de consolidación debido a que, si bien se han dado importantes pasos para la compatibilización del arbitraje con nociones e instituciones propias del Derecho Público, todavía incide significativamente en su desarrollo la frágil estabilidad del marco legal que lo contempla y la presencia de deficiencias regulatorias que no han podido coadyuvar a superar problemas suscitados en
\end{abstract}

[*] Profesor de la Facultad de Derecho de la Universidad Peruana de Ciencias Aplicadas (UPC). Máster en Derecho de la Contratación Pública por la Universidad de Castilla-La Mancha (España). Especialista en Gestión de Contratos Públicos por el Instituto para la Gestión Pública de la Organización de Estados Americanos (OEA). Especialista en Arbitraje Nacional e Internacional por la Universidad del Pacífico. Ha sido asesor de la Presidencia Ejecutiva y de la Dirección de Arbitraje del Organismo Supervisor de las Contrataciones del Estado (OSCE); así como asesor en arbitraje de la Gerencia de Promoción de la Inversión Privada de la Municipalidad Metropolitana de Lima y entre otros cargos. Fue secretario Técnico de la Comisión Legislativa constituida para la implementación de la Primera Disposición Final del Decreto Legislativo N. 1071 que norma el arbitraje. Dos veces primer puesto en la Competencia Internacional de Arbitraje Comercial Internacional organizada por la Universidad de Buenos Aires (Argentina), en las ediciones de los años 2008 y 2009.

Contacto: pcdedgar@upc.edu.pe 
la práctica arbitral relacionados a su propia aplicabilidad e, incluso, al rol de los árbitros. En ese sentido, el presente trabajo tiene por objetivo graficar - desde una perspectiva analíticael actual panorama del arbitraje en contrataciones con el Estado, a partir de las principales reglas incorporadas en las recientes modificaciones a la Ley $\mathrm{N} . \mathrm{O}$ 30225, Ley de Contrataciones del Estado, y a su Reglamento, cuya pertinencia y eficacia será objeto de reflexión en relación al contexto antes descrito, a partir de la ratio legis que se desprende de las mismas.

ABSTRACT: the importance of contracting with the State has given rise to the development of an increasingly broad and specialized regulatory framework, in the last twenty years, in which the arbitration figure has taken on a unique role, as the Peruvian legal order abstract of this mechanism of dispute resolution its origin features, giving itself own identity in this field of application. With the various regulatory changes that the regime has gone through, arbitration in contracting with the State has been object to numerous adjustments, as in the substantive as in the adjective, facing today a specialized discipline that is still in the process of consolidation due to, although important steps have been taken for the compatibility of arbitration with notions and institutions of Public Law, the fragile stability of the legal framework that contemplates it and the presence of regulatory deficiencies that have not been able to contribute to overcome problems raised in arbitration practice related to their own applicability, they still have a significant impact, and even to the role of arbitrators. In this sense, the present work aims to graph - from an analytical perspective - the current overview of arbitration in contracting with the State, based on the main rules incorporated in the recent amendments to Law N. ${ }^{\circ} 30225$, Law on State Contracting, and its Regulation, whose relevance and effectiveness will be object to reflection in relation to the context described above, based on the ratio legis that emerges from them.

PALABRAS CLAVE: conciliación y arbitraje, contratación pública, análisis costo-beneficio, institucionalidad arbitral, regulación y oportunidades de mejora.

KEY WORDS: conciliation and arbitration, public procurement, cost-benefit analysis, arbitration institutionality, regulation and improvement opportunities.

\section{INTRODUCCIÓN}

En el 2018, el Estado peruano adjudicó cerca de S/ 40600 millones como resultado de los procesos de contrataciones de bienes, servicios, obras y consultorías convocados en el mismo periodo, tanto por el Gobierno Central como por los Gobiernos Regionales y Locales $^{[1]}$. Dicha cifra explica la importancia de las contrataciones públicas como mecanismo de apalancamiento del desarrollo económico y social; desde el ámbito económico, el Estado es el principal comprador en el mercado nacional, por lo que el nivel y dimensión de la demanda de bienes y servicios de parte de las diversas entidades públicas constituye un factor dinamizante de la economía, representando importantes puntos porcentuales en nuestro PBI. Desde el ámbito social, la ratio de la contratación pública se explica, fundamentalmente, en que esta persigue la satisfacción oportuna y eficiente de necesidades públicas, en salvaguardia del interés público.

Ambos alcances (económico y social) constituyen indicadores del impacto de la contratación pública en el desarrollo del país; es, por ello, que el Estado ha desarrollado un marco dispositivo que tiene como propósito originario impulsar la estabilidad y seguridad en la realización del proceso de contratación en todas sus fases, bajo máximas ineludibles como son la transparencia, la eficiencia, la pluralidad de postores, la maximización del uso de los fondos públicos (value for money) y entre otros. Así, con el transcurrir del tiempo, el marco legal ha ido evolucionando hasta el punto de encontrarnos con una regulación bastante amplia y tecnificada.

[1] Recuperado de: https://public.tableau.com/profile/osce.bi\#!/vizhome/Informe Mensual-ConsolidadoDiciembre2018/IndicadoresdelMercadoEstatal 
Es a partir de la Constitución Política del Perú de 1993, a través de su artículo $76^{[2]}$, que se recoge la necesidad de garantizar que las contrataciones estatales se lleven a cabo mediante procedimientos particulares que permitan la obtención de bienes, servicios u obras de manera oportuna, con la mejor oferta económica y técnica, a través de un conjunto de deberes y derechos entre el Estado y el proveedor que propugnen principios como la imparcialidad, la libre competencia, el trato justo e igualitario entre postores, etc. (TC Expediente N. ${ }^{\circ}$ 020-2003$\mathrm{Al} / \mathrm{TC}, 2004)$. Como consecuencia de ello, desde el año 1998, las contrataciones y adquisiciones del Estado peruano cuentan con un orden jurídico uniforme, logrado inicialmente con la aprobación de la Ley $\mathrm{N}^{\circ} 26850$ y sus consiguientes normas reglamentarias y complementarias. Antes de dicha Ley teníamos al Reglamento Único de Licitaciones y Contratos de Obras Públicas (RULCOP) y el Reglamento Único de Adquisiciones (RUA), los cuales disponían procedimientos administrativos y de impugnación judicial (proceso contencioso administrativo). Dichas normas no contemplaban de forma alguna al arbitraje como mecanismo de solución de controversias. Incluso, se hablaba de una dicotomía entre los contratos privados y los contratos administrativos en relación al arbitraje, ya que solo los primeros podían ser sometidos a arbitraje (Cantuarias Salaverry, 2002, pp. 180-181).

Con dicho desarrollo normativo, no solo se incorporaron nociones, conceptos y tecnicismos más acordes a una regulación especial, estableciéndose disposiciones específicas con relación a las actuaciones preparatorias, los procedimientos de selección y la ejecución de contratos públicos; sino que, además, se incursionó en algunas innovaciones jurídicas como la regulación del arbitraje y la conciliación como los mecanismos legales para la solución de las controversias derivadas de los contratos públicos en ejecución, siendo el arbitraje el mecanismo de obligatorio sometimiento.

La incorporación del arbitraje en el Derecho Público peruano, a través de la normativa en contrataciones con el Estado, como un tipo de «arbitraje forzoso», no tiene parangón alguno en el Derecho Comparado. Esta decisión del legislador respondió en su momento a la necesidad de dotar de mayor «seguridad jurídica» a la dinámica Estado-proveedor, aparcando la competencia judicial ordinaria y prefiriendo un mecanismo que, conforme a nuestro ordenamiento constitucional, constituye una «jurisdicción especial»»[3]. Se trata de una situación particular en el contexto de América Latina, porque no solo se implantó la figura del arbitraje obligatorio (provocando escepticismo, debates e, incluso, cuestionamientos por parte de diversos arbitralistas), sino que, además, con su aplicación a los contratos públicos significó que el Estado peruano reconociera que no necesariamente resultaba ser - a través del Poder Judicial - el más indicado para administrar justicia particularmente en los conflictos derivados de las relaciones jurídicas que entabla con proveedores de bienes, servicios, obras o consultorías (Castillo y Sabroso, 2009, p. 13).

A partir de esta innovación legislativa, otros ordenamientos en la región viraron hacia el arbitraje, considerándolo como una alternativa plausible de aplicación; no obstante, en ninguno de los casos identificados, se optó por una fórmula igual de radical como la del ordenamiento peruano. Así, por ejemplo, Guatemala enmendó la Ley nacional de contratación del Estado para que las empresas puedan oponerse a la adjudicación de licitaciones por

[2] Constitución Política del Perú de 1993: «Artículo 76. Obligatoriedad de la Contrata y Licitación Pública: Las obras y la adquisición de suministros con utilización de fondos o recursos públicos se ejecutan obligatoriamente por contrata y licitación pública, así como también la adquisición o la enajenación de bienes. La contratación de servicios y proyectos cuya importancia y cuyo monto señala la Ley de Presupuesto se hace por concurso público. La ley establece el procedimiento, las excepciones y las respectivas responsabilidades.»

[3] Constitución Política del Perú de 1993: «Artículo 139. Principios de la Administración de Justicia: Son principios y derechos de la función jurisdiccional: 1. La unidad y exclusividad de la función jurisdiccional. No existe ni puede establecerse jurisdicción alguna independiente, con excepción de la militar y la arbitral. $[\ldots]$ ». 
medio del arbitraje, como consecuencia de la entrada en vigor del Tratado de Libre Comercio de Centroamérica y República Dominicana con Estados Unidos (CAFTA-RD) (Reporte SP/RRSSCPALC/DT N. ${ }^{\circ}$ 2-15, SELA, 2015, p. 15); por su parte, Colombia incorporó en la Ley N. ${ }^{\circ} 1563$ de 2012 la posibilidad de que los conflictos derivados de la contratación pública puedan ser llevados a un arbitraje técnico, siempre que así haya sido pactado en el referido contrato (La Torre, 2012). Y, más recientemente, Brasil emitió el Decreto N.․ 10.025 (Diário Oficial da União, 2019), a través del cual se establece la posibilidad de someter a arbitraje las disputas que se deriven de las contrataciones administrativas en los sectores portuario, transporte terrestre, ferroviario, fluvial y aeroportuario, en cuanto dichas controversias estén relacionadas, exclusivamente, a derechos patrimoniales vinculados con la recomposición del equilibrio económico-financiero de los contratos, el cálculo de las indemnizaciones derivadas de la terminación o transferencia de la asociación y el incumplimiento de las obligaciones contractuales por cualquiera de las partes ${ }^{[4]}$.

Los posteriores regímenes legales en el Perú (la Ley de Contrataciones y Adquisiciones del Estado, aprobada por Decreto Supremo N..$^{\circ}$ 0122001-PCM, su Reglamento aprobado por Decreto Supremo N. ${ }^{\circ}$ 013-2001-PCM; la Ley de Contrataciones y Adquisiciones del Estado aprobada por Decreto Supremo N. ${ }^{\circ}$ 083-2004-PCM, su Reglamento aprobado por Decreto Supremo N. ${ }^{\circ}$ 084-2004-PCM; y la Ley de Contrataciones del Estado, aprobada por Decreto Legislativo N. ${ }^{\circ} 1017$, con su Reglamento aprobado por Decreto Supremo N. ${ }^{\circ} 184-2008-E F$, incluyendo sus modificatorias aprobadas por la Ley N. ${ }^{\circ} 29873$ y el Decreto Supremo N. ${ }^{\circ}$ 138-2012-EF, respectivamente) han regulado el arbitraje con un mayor enfoque técnico, abstrayéndolo de sus características originarias y dotándole propias cuando de controversias derivadas de los contratos públi- cos se trate. Así, incluso, se le llegó a denominar «Arbitraje Administrativo», término que ha sido dejado de lado por la normativa vigente. No obstante, los referidos cambios normativos también son un claro indicador de cuán volátil ha sido la regulación de las contrataciones públicas en el último quindenio, circunstancia que no ha permitido la consolidación plena del arbitraje en esta materia como una institución jurídica; a ello se suma, la crisis de credibilidad que ha venido atravesando el mecanismo en los últimos años como consecuencia de riesgos de corrupción identificados a raíz del proceder de un grupo de árbitros, abogados, procuradores y contratistas, que han empleado al arbitraje como un medio para la colusión en favor de intereses particulares y en detrimento del interés público.

La última gran modificación del marco legal se dio en el año 2016 con la entrada en vigor de la Ley N. ${ }^{\circ} 30225$ y su Reglamento aprobado por el Decreto Supremo N. ${ }^{\circ} 350-2015-E F ;$ no obstante, se ha seguido la línea regulatoria antes descrita. Si bien el propósito de las nuevas disposiciones es fortalecer la aplicabilidad del mecanismo arbitral frente a los retos del contexto socioeconómico más reciente, dicho marco normativo comparado con el precedente pone en evidencia nuevamente cambios que no coadyuvan a la consolidación del propio mecanismo. La misma suerte ha seguido las modificatorias ulteriores a la Ley dadas vía el Decreto Legislativo N. ${ }^{\circ} 1341$ y el Reglamento aprobadas a través del Decreto Supremo N. ${ }^{\circ}$ 056-2017-EF.

Las modificaciones más recientes, aprobadas mediante el Decreto Legislativo N. ${ }^{\circ} 1444$, así como la consecuente modificación del Reglamento de la Ley N. ${ }^{\circ} 30225$ a través del Decreto Supremo N . $^{\circ} 344-$ 2018-EF (vigentes desde el 30 de enero de 2019), y —sobre este último- la aún más reciente modificación al Reglamento aprobada vía Decreto Supremo N. ${ }^{\circ}$ 377-2019-EF (publicado el 14 de diciembre de

[4] «[...] Art. 2 Poderão ser submetidas à arbitragem as controvérsias sobre direitos patrimoniais disponíveis. Parágrafo único. Para fins do disposto neste Decreto, consideram-se controvérsias sobre direitos patrimoniais disponíveis, entre outras:

I - As questões relacionadas à recomposição do equilíbrio econômico-financeiro dos contratos;

II - O cálculo de indenizações decorrentes de extinção ou de transferência do contrato de parceria; e

III - O inadimplemento de obrigações contratuais por quaisquer das partes, incluídas a incidência das suas penalidades e o seu cálculo. [...]”. 
2019), contemplan nuevas reglas de juego que terminan definiendo un régimen legal particular, que deberá coexistir con los regímenes anteriores en tanto sigan existiendo contratos derivados de procesos de selección convocados al amparo de las normas vigentes en aquel momento.

A efectos de comprender los alcances de las últimas modificaciones, resulta pertinente identificar, revisar y comentar las nuevas disposiciones con el objetivo de definir cuál es el panorama actual del arbitraje en contrataciones con el Estado. Cabe precisar que la premisa del presente trabajo es coadyuvar a la identificación de oportunidades de mejora que aún existen para el ordenamiento jurídico, resaltando, además, aquellos aportes que sí encaminan el proceso de consolidación que requiere el arbitraje en contrataciones con el Estado como un mecanismo estable y seguro.

\section{NUEVAS REGLAS: ALCANCES, EFECTOS PRÁCTICOS Y REFLEXIONES}

\subsection{Análisis costo-beneficio del arbitraje}

Cuando surge una controversia entre el contratista y el Estado, en el marco de la ejecución de un contrato público, se abre inmediatamente el camino para la evaluación y decisión acerca de cuál es el mejor esquema de solución para el caso concreto: someter la materia controvertida directamente al arbitraje o agotar previamente la posibilidad de conciliar. En la práctica, lo usual es que el análisis que realiza el contratista difiere del realizado por el Estado, ya que confluyen distintos factores de ponderación; mientras que para el contratista supone un ejercicio de ponderación eminentemente económico (relación costo-tiempo-resultado), para el Estado tradicionalmente el análisis se ha circunscrito a determinar cuál es el escenario que represente el menor riesgo para la gestión administrativa (relación resultado-responsabilidad funcional).

Esto último se explica, en primer lugar, en que las decisiones de la Administración Pública deben ser tamizadas a la luz del Principio de Legalidad; es decir, los funcionarios públicos solo pueden ejercer competencias y/o prerrogativas habilitadas expresamente por un mandato legal. Consecuentemente, la toma de decisiones más allá de lo previamente habilitado por la Ley podría suponer el desencadenamiento de responsabilidad administrativa funcional[ ${ }^{[5]}$. A ese escenario, se suma el hecho de que aún el país cuenta con un Sistema Nacional de Control persecutorio y no preventivo de las responsabilidades administrativas, aun cuando se han incorporado mecanismos de acompañamiento como el control concurrente o el control simultáneo.

En ese contexto, la decisión de optar por una conciliación antes que por un arbitraje ha sido casi siempre ajena a la lógica del funcionario público, por el temor de ser cuestionado en su elección, dado que — bajo la lógica tradicional del control administrativo- el funcionario está llamado a aplicar o agotar todos los mecanismos y procedimientos que el marco legal le habilita para el ejercicio de sus competencias y la cautela del interés público; así, la posibilidad de resolver directamente un conflicto derivado de un contrato público a través de un esquema autocompositivo como es la conciliación, potencialmente, podría representar para el funcionario el posterior hallazgo de responsabilidades bajo la premisa de no haber agotado el arbitraje que, además, de ser obligatorio por Ley es un mecanismo heterocompositivo que representaría -a diferencia de la conciliación- mayores seguridades y garantías para el Estado.

Esta línea de pensamiento aún está muy arraigada en la Administración Pública y es que, durante muchos años, no existieron lineamientos en el ordenamiento jurídico que permitieran un cambio significativo; por ejemplo, en los regímenes anteriores de contrataciones públicas no se delimitaba expresamente la responsabilidad de la decisión de conciliar por parte del Estado, lo que generaba confusión respecto a si dicha prerrogativa debía estar sujeta a la deliberación del área usuaria, del titular de la entidad o del procurador público. Sumado a ello, si bien el marco legal de la defensa jurídica del Estado faculta

[5] Ley N. ${ }^{\circ}$ 28175, Ley Marco del Empleo Público: «Artículo 19. Responsabilidades. Los empleados públicos son responsables civil, penal o administrativamente por el incumplimiento de las normas legales y administrativas en el ejercicio del servicio público.» 
a los procuradores públicos a conciliar o transigir, no explicita los alcances del ejercicio de dicha facultad cuando se trata de conflictos derivados de contratos públicos, más aún cuando ello tiene implicancias directas en el interés público y en el uso o destino de los fondos públicos afectos a la contratación ${ }^{[6]}$.

Con la Ley $\mathrm{N}^{\circ} 30225$ y su Reglamento, se recogieron por primera vez criterios clarificadores respecto a la potestad conciliatoria del Estado y a las condiciones para el empleo de este mecanismo como cuestión prearbitral. Así, con las últimas disposiciones incorporadas con el Decreto Legislativo $\mathrm{N} .{ }^{\circ} 1444$ y la consecuente modificatoria al Reglamento con el Decreto Supremo N. ${ }^{\circ} 344-2018$ $\mathrm{EF}$, se han establecido las siguientes reglas:

- La conciliación debe realizarse ante un conciliador y Centro de Conciliación acreditados por el Ministerio de Justicia y Derechos Humanos.

- Durante la conciliación o ante la propuesta de acuerdo conciliatorio, el titular de la entidad, con el apoyo de sus dependencias técnicas y legales, realiza el análisis costo-beneficio de proseguir con la controversia ya sea en la vía conciliatoria o en la vía arbitral, debiendo considerar en el análisis el costo en tiempo y recursos del proceso arbitral, la expectativa de éxito de seguir el arbitraje, la conveniencia de resolver la controversia en la instancia más temprana posible; así como los riesgos que representa la controversia en la normal ejecución del contrato público, incluso, el de no poder alcanzarse la finalidad de la contratación al no adoptarse un acuerdo conciliatorio.

- Constituye responsabilidad funcional del titular de la entidad o a quien este haya delegado la facultad de conciliar el impulsar o proseguir la vía arbitral cuando el análisis costo-beneficio determina que la posición de la entidad, razonablemente, no será acogida en dicha sede.
- En caso se arribe a un acuerdo conciliatorio total o parcial, la entidad debe cumplir con registrar el acta respectiva en el Sistema Electrónico de Contrataciones del Estado (SEACE), dentro del plazo de diez días de haberse suscrito la misma, bajo responsabilidad.

De las reglas antes citadas, la que representa el mayor avance regulatorio es la que incorpora la obligación de la entidad de efectuar un análisis costo-beneficio como condición sine qua non para el sometimiento de las controversias derivadas de la ejecución de un contrato público al arbitraje o a la conciliación prearbitral. Con ello, se impone un estándar de valoración de los factores contingentes que deberían orientar una mayor diligencia del Estado al momento de decidir cuál es el mecanismo de solución de conflictos más eficiente y efectivo en términos de costos económicos, tiempo y resultados; tan es así, que el referido análisis debe suponer el ejercicio comparativo de ventajas y desventajas que representarían el arbitraje frente a la conciliación y viceversa, sobre la base de criterios analíticos como el costo en tiempo y recursos del proceso arbitral, las probabilidades de éxito que tiene el Estado en un potencial arbitraje e, incluso, las repercusiones de llevar la solución del conflicto a un arbitraje respecto al objeto y finalidad del contrato público en ejecución.

De este modo, lo que busca la normativa vigente es romper los paradigmas en torno a la aplicación del arbitraje como único mecanismo efectivo y seguro para el Estado. En la práctica, es de público conocimiento que los costos económicos de un arbitraje son significativamente altos en comparación con los de una conciliación; asimismo, se sabe que un arbitraje puede durar en promedio varios meses e, incluso, años (dependiendo del tipo de controversita y de la gestión del proceso arbitral), frente a los pocos días que puede demandar un proceso conciliatorio. Por otro lado, respecto del instrumento que

[6] Decreto Legislativo N. ${ }^{\circ}$ 1068, del Sistema de Defensa Jurídica del Estado. «Artículo 23. De las atribuciones de los Procuradores Públicos: Son atribuciones y facultades generales de los Procuradores Públicos las siguientes: [...] 2. Los Procuradores Públicos podrán conciliar, transigir o desistirse de demandas, conforme a los requisitos y procedimientos dispuestos por el reglamento. Para dichos efectos será necesario la expedición de la resolución autoritativa del titular de la entidad, para lo cual del Procurador Público deberá emitir un informe precisando los motivos de la solicitud. [...]». 
pone fin al conflicto, si bien un laudo arbitral tiene los mismos atributos que una sentencia judicial de última instancia, un acta de acuerdo conciliatorio total tiene calidad de título de ejecución, por lo que la posibilidad del incumplimiento de compromisos $u$ obligaciones en ambos casos es similar, debiéndose incluso recurrir a los mecanismos de coacción asistida vía auxilio judicial. Entonces, vemos que la conciliación prearbitral puede configurarse como un mecanismo realmente eficiente, más aún cuando además de los factores antes mencionamos se suma la existencia de altas probabilidades de que el Estado pierda el conflicto de llevarse a cabo un arbitraje; así, el camino que se traza es el de mirar progresivamente al arbitraje como un mecanismo residual cuyos costos y tiempos se justifiquen plenamente si las condiciones y características del conflicto permiten una efectiva defensa fáctica y jurídica del interés público.

\subsection{Requisitos y condiciones para ser árbitro}

Las legislaciones arbitrales, en su gran mayoría, establecen requisitos mínimos que deben cumplir aquellas personas que potencialmente actúen como árbitros, los cuales están generalmente referidos a la capacidad, profesión o impedimentos de las personas (Cantuarias, 2006). En el Perú, esos requisitos mínimos generales están regulados en el Decreto Legislativo N. ${ }^{\circ} 1071$ que norma el arbitraje ${ }^{[7]}$, que establece la posibilidad de que una persona natural pueda ser árbitro siempre que se halle en pleno ejercicio de sus derechos civiles y no tenga incompatibilidades para actuar como tal. La primera exigencia supone que todo aquel que pretenda ser árbitro debe ser una persona física que tenga capacidad de obrar; es decir, que sea idónea y apta para ejercer derechos y obligaciones, así como también para hacer parte de actividades y relaciones jurídicas (Rodríguez, 2011, p. 131). Por su parte, la segunda está orientada a verificar que no exista una prohibición sobre la persona que implique la imposibilidad de realizar determinadas actividades cuando se encuentren en situaciones específicas -en este caso, el ser designado como árbitro-, sin que esto suponga que carecen o tengan limitada su capacidad de obrar (Rodríguez, 2011, p. 134).

Estos requisitos generales no son suficientes cuando hablamos de arbitraje en contrataciones con el Estado; y es que, desde la derogada Ley de Contrataciones del Estado aprobada por el Decreto Legislativo $\mathrm{N} .{ }^{\circ} 1017$ hasta el actual marco legal, se ha impuesto la exigencia de que los profesionales que quieran ejercer la función arbitral en este ámbito deban cumplir con acreditar una serie de requisitos y condiciones específicas.

Así, con la dación del Decreto Legislativo N. ${ }^{\circ}$ 1444 , se ha consolidado dicha tendencia estableciéndose en su artículo 45 , incisos 45.15 y 45.16 , que el árbitro único o el presidente de un tribunal arbitral deben ser necesariamente abogados que cuenten con especialización acreditada en Derecho Administrativo, Arbitraje y Contrataciones con el Estado; los demás integrantes del tribunal arbitral pueden ser expertos o profesionales en otras materias, debiendo necesariamente tener conocimiento en contrataciones con el Estado. Pero, además de todas esas exigencias, el citado artículo establece que en caso de que el árbitro sea designado por el Estado -ya sea en un arbitraje institucional como en uno ad hoc - se requiere que dicho profesional se encuentre previamente inscrito en el Registro $\mathrm{Na}$ cional de Árbitros (RNA) administrado por el Organismo Supervisor de las Contrataciones del Estado (OSCE); de igual manera, esta exigencia es obligatoria en el caso de designación residual del presidente de un tribunal arbitral, tanto en un arbitraje institucional como ad hoc.

Respecto al requisito relativo a la especialización acreditada en Derecho Administrativo, Arbitraje y Contrataciones con el Estado, en la práctica arbitral existen voces divididas sobre la idoneidad y/o pertinencia de este parámetro. Desde una posición crítica, hay quienes sostienen que dicho um-

[7] Decreto Legislativo N. ${ }^{\circ}$ 1071: «Artículo 20. Capacidad. Pueden ser árbitros las personas naturales que se hallen en el pleno ejercicio de sus derechos civiles, siempre que no tengan incompatibilidad para actuar como árbitros. Salvo acuerdo en contrario de las partes, la nacionalidad de una persona no será obstáculo para que actúe como árbitro.» 
bral solo es alcanzado por un universo limitado de profesionales, lo que no permitiría una mayor pluralidad de actores intervinientes en calidad de árbitros; por otro lado, se ha llegado a sostener que dicha exigencia no es adecuada si lo que busca es garantizar que quienes participen como árbitros en arbitrajes en contrataciones con el Estado sean realmente expertos en las materias involucradas, tanto en relación al fondo de las materias controvertidas como a nivel de la gestión de proceso arbitral, señalándolo incluso como requisito pernicioso porque privilegiaría la acreditación formal de grados o títulos académicos como único indicador del expertise que se requiere para ejercicio de la función arbitral, en detrimento de la posibilidad de acreditar ello a través de experiencia laboral y/o profesional en dichas materias, así como mediante la trayectoria académica y la docencia universitaria. En contraste, quienes acogen positivamente este estándar indican, principalmente, que se trata de un requisito objetivo y verificable, que reduce la discrecionalidad y el subjetivismo al momento de valorar y calificar el perfil profesional de los profesionales que puedan ejercer la función arbitral.

Más allá de las posiciones antes descritas, es menester reconocer que la Ley podría haber recogido de mejor manera un estándar de esa naturaleza; en esa línea, debería prevalecer en el análisis el poder considerar que este requisito formal no es el fin en sí mismo, sino que es el medio por el cual, complementariamente a otros factores de ponderación, se debería permitir a los profesionales más idóneos - tanto términos de conocimientos como de competencias- asumir la importante responsabilidad de administrar justicia en los diversos conflictos suscitados entre los proveedores y el Estado. Es decir, no debería entenderse como propósito de la Ley permitir que quienes cuenten con una triple especialidad académicamente certificada puedan ser considerados árbitros por el hecho de haberlo acreditado; sino que, por el contrario, se espera que quienes reúnan las cualidades y aptitudes necesarias para ser árbitro cuenten además con estudios, grados y títulos de especialidad que los respalden. En ese sentido, constituye un despropósito creer que dicho estándar per se ha de garantizar la idoneidad que se requiere en los árbitros en materia de contratación pública; por lo que resulta necesario que el ordenamiento jurídico compatibilice este tipo de exigencias no solo con otros importantes criterios como son la experiencia y trayectoria profesional, a través de parámetros objetivos y verificables, sino también con los estándares éticos previstos en la Ley y su Reglamento. En ese orden de ideas, es preciso señalar que, en aras de la consolidación del arbitraje en contrataciones con el Estado como una disciplina especializada, no debería ser una opción para el legislador flexibilizar o eliminar requisitos y/o estándares exigibles a quienes busquen participar como árbitros, sino perfeccionarlos de modo que permitan lograr su finalidad esencial. Sin duda, existe una oportunidad de mejora sobre este extremo.

Por otro lado, respecto del requisito de estar previamente inscrito en el RNA, de la revisión de la versión del Reglamento de la Ley modificada por el Decreto Supremo N. ${ }^{\circ} 344-2018-E^{[8]}$, se advertía que los alcances al interior del mismo variaban diametralmente en contraste con lo estipulado en la Ley. Así, por un lado, el artículo 230 del Reglamento señalaba:

«[...] 230.3 En los arbitrajes institucionales, la institución arbitral verifica que los árbitros cumplan con los requisitos establecidos en el numeral 45.15 del artículo 45 de la Ley.

230.4. Para desempeñarse como árbitro en los arbitrajes ad hoc, se requiere estar inscrito en el Registro Nacional de Árbitros (RNA-OSCE). $[\ldots]$ ».

No obstante, por otro lado, el artículo 242.1 del Reglamento define al RNA como el listado de profesionales que pueden desempeñarse como árbitros cuando una entidad los designe en arbitrajes institucionales o ad hoc, y para efectos de designaciones residuales ${ }^{[9]}$.

[8] Antes de la modificatoria aprobada por el Decreto Supremo N. ${ }^{\circ}$ 377-2019-EF, del 14 de diciembre de 2019.

[9] Artículo 232 del Reglamento de la Ley de Contrataciones del Estado (versión del DS N. ${ }^{\circ}$ 344-2018-EF - Vigente): «232.1. En aquellos procesos arbitrales ad hoc en los cuales las partes no hayan pactado la forma en la que 
De la lectura sistemática de las disposiciones antes citadas y de lo estipulado en el artículo 45.16 de la Ley, era de advertirse una contradicción entre lo señalado por la Ley y lo regulado por el artículo 230.4 del Reglamento en lo relativo a la exigibilidad del RNA como requisito para ser árbitro en arbitrajes ad hoc. Mientras que la primera norma dispone - de manera específica - que esta exigencia se circunscribe al supuesto del profesional designado como árbitro por el Estado, tanto para arbitrajes ad hoc como institucionales, el Reglamento señalaba —en términos más amplios y generales-que dicha exigencia es necesaria para el caso de profesionales que se desempeñen como árbitros en los arbitrajes ad hoc, sin mayor referencia a las otras condiciones expresadas en la Ley. Entonces, surgían las preguntas: ¿el RNA es exigible solo a los árbitros designados por una entidad pública en los arbitrajes ad hoc o también en los arbitrajes institucionales?, ¿ocurre lo mismo en el caso de las designaciones residuales de árbitros?, ¿el requisito también podía entenderse exigible a los árbitros designados por el contratista en los arbitrajes ad hoc?

Con la más reciente modificatoria al Reglamento de la Ley, aprobada por Decreto Supremo N. ${ }^{\circ}$ 377-2019-EF, se reformularon los términos del artículo 230.4 de la siguiente manera: «[...] 230.4. Para desempeñarse como árbitro, conforme a lo previsto en el numeral 242.1 del artículo 242 , se requiere estar inscrito en el Registro Nacional de Árbitros (RNA-OSCE). El procedimiento de inscripción de árbitro en el RNA-OSCE es de evaluación previa con aplicación del silencio administrativo [...].» De este modo, se ha buscado corregir la contradicción descrita en los párrafos previos, privilegiándose los alcances y sentido aplicativo de lo establecido en el artículo 45 de la Ley sobre lo señalado en el artículo 230 del Reglamento; en ese sentido, ahora queda claro que la exigencia de la inscripción de un profesional en el RNA se aplica, tanto en arbitrajes institucionales como ad hoc, solo en los siguientes supuestos: i) cuando el profesional sea designado como árbitro por parte del Estado; o ii) cuando se trate de la designación residual de un árbitro único o presidente de tribunal arbitral.

Sin perjuicio de lo antes expuesto, resulta inevitable cuestionarse acerca de cuál es la ratio legis detrás del establecimiento de un requisito como la inscripción previa de un profesional en el RNA como condición sine qua non para poder ejercer la función arbitral. Al respecto, debemos partir evidenciando que la inscripción en dicho registro supone el agotamiento previo de un procedimiento administrativo, el cual — hoy en día - ya no es de aprobación automática, sino de evaluación previa, lo cual ha sido enfatizado con la modificación del Reglamento de la Ley a través del Decreto Supremo N. ${ }^{\circ} 377-2019$ $\mathrm{EF}^{[10]}$. Pese a ello, dicho registro no reúne todas las características legales y doctrinales para que sea categorizado como un registro público, porque no tiene como finalidad hacer oponible un derecho a terceros, ni como un registro administrativo, por

se designa a los árbitros o no se hayan puesto de acuerdo respecto a la designación del árbitro único o algún árbitro que integre el Tribunal Arbitral, o los árbitros no se hayan puesto de acuerdo sobre la designación del presidente del Tribunal Arbitral, cuando corresponda, cualquiera de las partes puede solicitar al OSCE la designación residual, la que se efectúa a través de una asignación aleatoria por medios electrónicos, de acuerdo a los plazos y procedimiento previstos en la Directiva correspondiente.

232.2. Para la designación residual del presidente del Tribunal Arbitral o del árbitro único en un arbitraje institucional, el árbitro a designarse está inscrito en el RNA-OSCE.

232.3. Las designaciones residuales efectuadas por el OSCE se realizan del RNA-OSCE, y son definitivas e inimpugnables.»

[10] Artículo 230 del Reglamento de la Ley de Contrataciones del Estado (versión del DS N. ${ }^{\circ}$ 377-2019-EF - Vigente):

«[...] 230.4. [...] El procedimiento de inscripción de árbitro en el RNA-OSCE es de evaluación previa con aplicación del silencio administrativo negativo y tiene un plazo de treinta (30) días hábiles. Los plazos y procedimientos para la designación y aceptación de árbitros en arbitrajes ad hoc se establecen en la directiva aprobada por el OSCE.» 
cuanto la finalidad del mismo no es la configuración de un título habilitante ${ }^{[11]}$ para el ejercicio de un derecho preexistente, ya que los árbitros no ejercen propiamente una actividad económica regulada, sino que detentan el atributo de ejercer una potestad jurisdiccional especial a la luz del artículo 139 de la Constitución Política del Perú.

Entonces, se puede sostener que el RNA es un registro sui generis que tiene por principal finalidad hacer pública la nómina de individuos, previamente calificados, que pueden ser designados como árbitros por el Estado y de forma residual (como presidente del Tribunal Arbitral o Árbitro Único), tanto para arbitrajes institucionales como ad hoc; por lo que es posible entender que la razonabilidad de su existencia y exigencia se justifiquen en la necesidad de transparentar la información sobre la idoneidad de los profesionales que aspiran ejercer la función arbitral, cuya evaluación o procesamiento sirven para la toma de una decisión por parte del Estado.

Sin embargo, esta razonabilidad no justifica en opinión del suscrito- la decisión del legislador de apartar de la exigencia del RNA a los árbitros designados por los contratistas, sobre todo si tenemos internalizada la premisa de que el éxito del arbitraje depende de la idoneidad, probidad, competencia y capacidades de los árbitros que intervengan, indistintamente si son designados por el Estado, por los contratistas o por las instituciones arbitrales; por lo que una diferenciación en los estándares o condiciones formales a ser exigidos a los profesionales que aspiren a ejercer la función arbitral, en razón a quien es la parte que lo designa, no solo constituye un despropósito, sino que puede generar incentivos para que existan profesionales que busquen afianzar perfiles como árbitros «de contratistas» 0 «de entidades públicas», en clara oposición a la neutralidad y a la experiencia diversificada que se busca naturalmente en un árbitro.

Mención aparte merece el establecimiento de una serie de supuestos configurativos de impedimentos o incompatibilidades para ejercer la función arbitral en materia de contrataciones con el Estado. Y es que, con ello, el ordenamiento presume que la justicia arbitral idónea no puede recaer en manos de personas que no posean las calificaciones legales para ser árbitros o que, aun teniéndolas, estén impedidas de serlo en virtud de una circunstancia transitoria: el cargo público que ocupan [12].

En esa línea, en el artículo 231 del Reglamento vigente se establece taxativamente una lista cerradas de impedimentos para ejercer la función arbitral, los cuales recaen principalmente en funcionarios públicos sobre los cuales puede configurarse implícitamente un potencial conflicto de interés; por ejemplo, se encuentran incursos en dichos impedimentos los funcionarios de alto nivel (como el presidente de la República, congresistas, titulares de Organismos Constitucionalmente Autónomos, magistrados, el contralor general), los funcionarios con poder territorial (gobernadores regionales y alcaldes provinciales y distritales) y los funcionarios con relacionamiento sectorial (aquellos que tengan vínculo directo o indirecto con la entidad o sector que interviene en el arbitraje, dentro de los límites establecidos por las normas de incompatibilidades para la función pública).

[11] «[...] En general, la doctrina y los ordenamientos jurídicos emplean indistintamente los vocablos "autorización", "permisos", "habilitación", "licencias", etcétera. Lo cierto es que el título habilitante (España) o la habilitación administrativa (Francia) son el género, y los permisos, habilitaciones, autorizaciones o licencias, $\mathrm{u}$ otros, incluso, las mismas concesiones administrativas, son una especie de aquellos. [...] El género de título habilitante es, pues, una técnica de comprobación de la satisfacción de los requisitos previstos por la legislación aplicable, previa al momento en el que el particular puede iniciar lícitamente la actividad. Por tanto, es posible afirmar su existencia solo en aquellos supuestos en los que el inicio de la actividad se encuentra prohibido ex ante, de modo que, en caso de no obtenerse, el inicio y desarrollo de la actividad es antijurídico.». Cfr. ARAUJO-JUÁREZ, José. Los títulos habilitantes en materia de telecomunicaciones en Venezuela. Biblioteca Jurídica Virtual del Instituto de Investigaciones Jurídicas de la UNAM (México), p. 175 (Ver: https://archivos.juridicas.unam.mx/www/bjv/libros/7/3043/8.pdf).

[12] Cfr. CASTILLO FREYRE, Mario y SABROSO, Rita. El Arbitraje en la Contratación Pública. Biblioteca de Arbitraje. Lima: Palestra, 2009, p. 192. 
La no incursión en dichos supuestos constituye también una condición esencial para que un profesional pueda ser designado como árbitro, la cual debe ser observada oportunamente tanto por el contratista como la entidad; en el caso de esta última, la normativa actual enfatiza que la responsabilidad de la elección del árbitro recae en el titular de la entidad o a quien este haya delegado tal facultad ${ }^{[13]}$.

Cabe mencionar que el referido artículo 231 del Reglamento ha sido recientemente modificado con la dación del Decreto Supremo N. ${ }^{\circ} 377-2019-$ $E F$, a través del cual se ha corregido un craso error incurrido en la versión anterior del artículo: la doble regulación del impedimento para los sancionados con inhabilitación o con suspensión de la función arbitral establecidas por el Consejo de Ética; esto debido a que en la versión anterior dicho supuesto se encontraba contemplado innecesariamente tanto en el literal $\mathrm{m}$ ) como en el literal t) ${ }^{[14]}$ (este último eliminado con la reciente modificación).

\section{EL ARBITRAJE INSTITUCIONAL VS. EL AR- BITRAJE AD HOC}

Más allá de la tradicional dicotomía que supone la elección entre un arbitraje institucional o un ad hoc, lo cierto es que actualmente hay mayor información y conciencia sobre los alcances de cada uno de estos tipos de arbitraje; ello, gracias al efecto dinamizador que ha representado la incorporación del arbitraje como mecanismo de solución de controversias en materia de contrataciones con el Estado, impulsando el crecimiento de la práctica arbitral y el desarrollo del Perú como plaza arbitral en la región.

No obstante, la regulación detrás ha jugado un rol particularmente importante en el posicionamiento de uno u otro tipo de arbitraje. En un inicio, con reglas poco estables y que incluso desnaturalizaron en un determinado momento la verdadera utilidad de cada tipo de arbitraje; hoy, ese marco regulatorio se corrige a sí mismo y busca establecer reglas más sostenibles y acordes con los tecnicismos que demanda un mecanismo especial como lo es el arbitraje en contrataciones con el Estado.

En los últimos años, se ha transitado de un esquema en donde la figura del arbitraje ad hoc era preeminente ${ }^{[15]}$, hacia a un escenario en donde el arbitraje ad hoc pareciera estar proscrito, reduciéndose significativamente el ámbito de su aplicación ${ }^{[16]}$. Este escenario ha sido el reflejo del proceso

[13] Artículo 230 del Reglamento de la Ley de Contrataciones del Estado (versión del DS N. ${ }^{\circ}$ 344-2018-EF - Vigente):

«[...] 230.2. Tanto en el arbitraje institucional como en el ad hoc la designación del árbitro por parte de la entidad es aprobada por su titular o por el servidor en quien este haya delegado tal función; sin perjuicio de la verificación oportuna que realice la institución arbitral y el contratista. [...]».

[14] Artículo 231 del Reglamento de la Ley de Contrataciones del Estado (versión del DS N. ${ }^{\circ}$ 344-2018-EF

- Derogada):

«231.1. Se encuentran impedidos para ejercer la función de árbitro:

$[\ldots]$

m) Los sancionados con inhabilitación o con suspensión de la función arbitral establecidas por el Consejo de Ética, en tanto estén vigentes dichas sanciones, sin perjuicio de la culminación de los casos en los que haya aceptado su designación previamente a la fecha de imposición de la sanción.

$[\ldots]$

t) Las personas sancionadas por el Consejo de Ética según lo dispuesto en este Reglamento.»

[15] Con los regímenes de la Ley de Contrataciones y Adquisiciones del Estado, aprobada por Decreto Supremo N. ${ }^{\circ}$ 012-2001-PCM, su Reglamento aprobado por Decreto Supremo N. ${ }^{\circ}$ 013-2001-PCM, y la Ley de Contrataciones y Adquisiciones del Estado aprobada por Decreto Supremo N. ${ }^{\circ}$ 083-2004-PCM, su Reglamento aprobado por Decreto Supremo N. ${ }^{\circ}$ 084-2004-PCM.

[16] Desde el régimen de la Ley de Contrataciones del Estado, aprobada por Decreto Legislativo N. ${ }^{\circ} 1017$, y su Reglamento aprobado por Decreto Supremo N. ${ }^{\circ} 184-2008-E F$, sus modificatorias aprobadas por Ley N. ${ }^{\circ}$ 
evolutivo del pensamiento del legislador, el cual en un inicio concibió al arbitraje ad hoc como la regla general, desnaturalizando la esencia excepcional de dicho esquema procesal (de allí su propio nombre).

Hablar de un arbitraje ad hoc es referirnos a un proceso caracterizado por la flexibilidad con la que pueden definirse las reglas aplicables, ya que son las propias partes las que tienen la posibilidad de diseñar un arbitraje a la medida de las características de la controversia (plazos, actuaciones, etapas y entre otros). Asimismo, a diferencia del arbitraje institucional, en el ad hoc no existe el respaldo de una institución que predefina un esquema organizacional formal al que las partes y los árbitros deben someterse.

Dadas estas características y considerando la tendencia garantista en la regulación del derecho de la contratación pública, llama poderosamente la atención por qué el legislador peruano ha considerado inicialmente al arbitraje ad hoc como el mecanismo ideal, teniendo presente además que las controversias que surgen en materia de contrataciones con el Estado comprometen aspectos relacionados al interés público y el destino de fondos públicos, requiriendo, por lo tanto, esquemas de mayor seguridad, formalidad y predictibilidad. Este antecedente se explica a través de los siguientes datos y cifras:

- Según estudio del Banco Mundial del 2011 (Kundmüller y Rubio, 2011), elaborado sobre un universo de 1400 laudos publicados por OSCE y por otros centros de arbitraje correspondientes al periodo 1998-2010, el Perú era probablemente el único país del mundo en el que el arbitraje ad hoc competía con el arbitraje institucional, considerando que en otras jurisdicciones el arbitraje ad hoc es una práctica residual. Del universo de laudos analizados, el referido estudio concluyó que un 55 $\%$ de los arbitrajes en contrataciones con el Estado eran ad hoc.
- Por su parte, según el estudio del Centro de Arbitraje de la Pontificia Universidad Católica del Perú de 2014 (Guzmán-Barrón y Zúñiga, 2014), elaborado sobre una muestra de 400 laudos de un total de 2040 laudos publicados por el OSCE correspondientes al periodo 2003-2012, se determinó que el $71.8 \%$ de los arbitrajes en los que participa el Estado eran ad hoc.

- En el año 2015, la Contraloría General de la República también publicó un estudio sobre los arbitrajes en materia de contrataciones con el Estado, el cual fue elaborado sobre un universo de 2796 laudos publicados por el OSCE, correspondientes al periodo 2003-2013 (Contraloría General de la República, 2015). De los laudos referidos, el estudio concluyó que el 62 $\%$ de los casos el arbitraje era ad hoc y solo el $37 \%$ era institucional.

- Del análisis de laudos arbitrajes en materia de obras registrados ante OSCE, correspondientes a los años 2012, 2013, 2014, 2015 y 2016, en donde la materia controvertida deriva de la resolución contractual aplicada tanto por entidades como por contratistas, la Dirección de Arbitraje del OSCE identificó que en promedio el $80 \%$ de los laudos revisados provenían de arbitrajes ad hoc, siendo el Estado la parte demandada en el $95 \%$ de casos $^{[17]}$.

Los datos antes expuestos permiten apreciar la correlación que existía entre las cifras que reflejan la preminencia que tuvo el arbitraje ad hoc y las que, a su vez, demuestran que el Estado era, en la mayoría de casos, la parte demandada. Esto no significa que el arbitraje ad hoc sea per se un mecanismo inadecuado para el Estado; no obstante, dichos indicadores pusieron los reflectores en la fórmula legislativa optada hasta entonces, motivando la necesidad de un replanteamiento profundo. Aunado a ello, se dieron a conocer, casos en donde el arbitra-

29873 y el Decreto Supremo N. ${ }^{\circ} 138-2012-E F$, hasta el régimen más reciente de la Ley $N .^{\circ} 30225$ y su Reglamento.

[17] Análisis trimestrales de entre 20 y 30 laudos arbitrales por parte de la Dirección de Arbitraje del OSCE. La información corresponde a los resultados de los informes de análisis emitido sobre el II, III y IV trimestre del 2016. 
je ad hoc fue empleado para diseñar «a medida» un esquema de actos orientados a perpetrar actos de corrupción en perjuicio del Estado; algunos de los casos más sonados en los últimos cuatro años han sido los siguientes:

- Caso Rodolfo Orellana: tribunales arbitrales ad hoc formaban parte de una organización criminal orientada a favorecer indebidamente intereses particulares en controversias tanto con privados como con entidades públicas. Un ejemplo de este último ha sido el caso arbitral con el Gobierno Regional de Arequipa y Oncoserv Arequipa (Bazo, 2015).

- Caso Gobierno Regional de Tumbes: El expresidente regional de Tumbes, Gerardo Viñas Dioses, fue condenado a 11 años de prisión por coludirse con el procurador regional, un empresario y un árbitro legal para defraudar al Estado por S/ 9,2 millones de soles. La sentencia, dictada por la jueza María Guillén Ledesma, del $1 .^{\circ}$ Juzgado Unipersonal Nacional, también incluyó al presidente del tribunal arbitral, a quién se le impuso 12 años de prisión. Esta es la primera sentencia que se dicta contra el integrante de un tribunal arbitral. Los otros dos árbitros miembros del Tribunal Arbitral fueron absueltos ${ }^{[18]}$.

Los casos antes citados son evidencia del mal empleo del arbitraje ad hoc cuando de intereses particulares se trata, lo que invita a reflexionar sobre cuán vulnerable es el arbitraje a los riesgos de la corrupción. Así, debemos considerar que dicha vulnerabilidad se mide en razón de dos (2) factores fundamentales: i) las garantías que el tipo de arbitraje elegido proporciona; y ii) el perfil del árbitro o los árbitros a cargo del arbitraje.

Sobre el primero, es objetivo e incuestionable que el arbitraje institucional brinda mayores seguridades y garantías que el arbitraje ad hoc, sobre todo cuando el Estado es parte y las controversias involucran asuntos de interés público y fondos públicos. Así, factores como la predictibilidad, la especialidad, la sostenibilidad, la responsabilidad administrativa, la autorregulación institucional y la competitividad permiten organizar y administrar un arbitraje con mayores seguridades para sus agentes. Ello no significa que el arbitraje ad hoc automáticamente sea malo y perjudicial, solo que cuando es empleado como «la regla» y no como la «excepción» resulta más propenso a desnaturalizarse y convertirse en un instrumento sin las garantías ni seguridades que un agente como el Estado requiere para arbitrar las controversias derivadas de contratos públicos. Sobre el segundo factor, el elemento subjetivo del arbitraje personificado en el árbitro independiente, imparcial, probo e idóneo para el caso, constituye clave para éxito del proceso. Si sumamos estas cualidades del árbitro con un esquema arbitral de mayores seguridades y garantías como el institucional, los riesgos a los que nos referíamos líneas arribas (según las cifras y los casos de corrupción) podrían verse mitigados significativamente.

Ante esa realidad, con la Ley $\mathrm{N} .^{\circ} 30225$ y sus posteriores modificatorias, el ordenamiento jurídico estableció expresamente el carácter excepcional del arbitraje ad hoc, siendo la nueva regla general el sometimiento de las controversias en materia de contrataciones con el Estado a los arbitrajes institucionales. El primer antecedente de este nuevo enfoque se dio con la emisión del informe final de la Comisión Presidencial de Integridad sobre medidas anticorrupción, presentado el 4 de diciembre del 2016; así, dentro de las denominadas «Medidas para Promover la Integridad y Prevenir y Sancionar la Corrupción», se propuso en el punto 34 «Establecer que el arbitraje en materia de contratación pública sea únicamente institucional, tomando en cuenta las ventajas que tiene este sobre el arbitraje ad hoc en materia de transparencia, seguridad y predictibilidad» (Comisión Presidencial de Integridad, 2016). A esta posición de plegaron instituciones como la Defensoría del Pueblo y Transparencia Internacional, quienes expresaron la necesidad de ajustar la normativa a efectos de fortalecer la institucionalidad de los arbitrajes derivados de la ejecución de contratos públicos.

[18] Recuperado de: http://larepublica.pe/impresa/politica/818547-sentencian-vinas-dioses-y-arbitro-legalpor-colusion 
Con la dación del Decreto Legislativo N.$^{\circ} 1341$ y su respectivo Reglamento aprobado por el Decreto Supremo N. ${ }^{\circ}$ 056-2017-EF, se incorporó por primera vez límites objetivos para la aplicación del arbitraje ad hoc; así, se estipuló que dicho tipo de arbitraje solo era aplicable para contratos de bienes, servicios y consultoría en general (excluyéndose a los contratos de obras y consultorías de obra), cuyos montos contractuales originales sean menores o iguales a veinticinco (25) Unidades Impositivas Tributarias (UIT). Asimismo, en la línea del fortalecimiento de la institucionalidad arbitral, se estableció que solo los arbitrajes con el Estado podrían ser llevados a cabo ante instituciones o centros de arbitraje previamente acreditados por el OSCE; sin embargo, este último extremo de la normativa no llegó a efectivizarse debido a que el OSCE no implementó el sistema de acreditación de instituciones arbitrales.

Mediante la última modificación de la Ley $\mathrm{N}$. $^{\circ}$ 30225 vía el Decreto Legislativo N. ${ }^{\circ}$ 1444, se dispuso que el Reglamento desarrollará los supuestos de aplicación del arbitraje ad hoc ${ }^{[19]}$. De esta manera, el artículo 225.3 del Reglamento, aprobado por Decreto Supremo N. ${ }^{\circ} 344-2018-E F$, estableció inicialmente que las partes pueden recurrir al arbitraje ad hoc cuando las controversias deriven de contratos cuyo monto contractual original sea menor o igual a cinco millones con 00/100 soles (S/ 5000 000, $00)$; no obstante, con la reciente modificación del Reglamento aprobado por Decreto Supremo N. 377-2019-EF, se cambió la base de cálculo del tope presupuestario, pasando del valor del monto contractual original al valor estimado o valor referencial del proceso de selección del cual deriven las controversias a ser sometidas a arbitraje.

Desde una perspectiva general, estos últimos cambios vislumbran un camino más claro hacia la preminencia del arbitraje institucional como regla general, por cuanto han precisado el alcance excepcional del arbitraje ad hoc sobre la base de un único criterio: el monto o valor de la fuente de controversia (tope presupuestario). Si bien dicho criterio resulta útil en la búsqueda de un parámetro objetivo, lo cierto es que dadas las características intrínsecas del arbitraje ad hoc, hubiese sido mucho más útil y eficiente que se estructuraran otros parámetros más acordes con la naturaleza excepcional de dicho tipo de arbitraje, tales como las características especiales y complejidad de la materia controvertida, la incidencia del arbitraje en la consecución final del objeto contractual y/o en la ejecución última del contrato público, así como la necesidad de llevar a cabo actuaciones especiales que ameritan reglas extraordinarias diseñadas por las partes y/o los árbitros; de modo que existan mayores razones que la mera cuantía del proceso de selección para justificar la aplicación excepcional de un esquema procesal flexible y célere como lo es el arbitraje ad hoc.

Por su parte, si bien el arbitraje institucional se avizora como un escenario más acorde con las expectativas de seguridades y garantías que requiere el Estado en cuanto a la gestión de los conflictos en materia de contratos públicos, los lineamientos vigentes deben ir acompañados de disposiciones más claras sobre el rol y responsabilidades de los centros de arbitraje, sobre todo para que el componente burocrático de dichas instituciones no se configure con el tiempo en un obstáculo para el acceso a la justicia arbitral, ya sea a través de la exigencia de excesivas formalidades, aplicación de tiempos administrativos desproporcionales con relación a la celeridad que en esencia debe guardar el arbitraje, cobros exorbitantes de tarifas o conceptos administrativos, poca transparencia en la designación residual de árbitros y entre otros. En ese orden de ideas, considerando que el efecto directo de la regla impuesta por la Ley $\mathrm{N} .^{\circ} 30225$ y sus últimas modificatorias es el reconocimiento de un mercado cautivo para las instituciones arbitrales, se espera que estas asuman con plena responsabilidad el compromiso de autorregularse permanentemente

[19] Artículo 45 del TUO de la Ley de Contrataciones del Estado:

«45.1 Las controversias que surjan entre las partes sobre la ejecución, interpretación, resolución, inexistencia, ineficacia o invalidez del contrato se resuelven, mediante conciliación o arbitraje, según el acuerdo de las partes. En el reglamento se definen los supuestos para recurrir al arbitraje ad hoc. Las controversias sobre la nulidad del contrato solo pueden ser sometidas a arbitraje. [...]». 
en aras de coadyuvar al fortalecimiento de la institucionalidad y del mercado arbitral. En ese sendero, destacan por sus importantes esfuerzos a nivel nacional instituciones arbitrales como el Centro de Arbitraje de la Cámara de Comercio de Lima (CCL), el Centro de Arbitraje de la Cámara de Comercio Americana del Perú (AmCham) y el Centro de Análisis y Resolución de Conflictos de la Pontificia Universidad Católica del Perú (PUCP); no obstante, corresponde ser especialmente vigilantes a este proceso en el interior del país, en donde aún persisten brechas que cerrar para el fortalecimiento de la institucionalidad en la gestión de los arbitrajes.

\section{REFLEXIONES FINALES}

El dinamismo que - con el tiempo- ha alcanzado el arbitraje en contrataciones con el Estado y su progresivo reconocimiento como disciplina especializada ha traído consigo algunos retos para el ordenamiento jurídico. En esa línea, si bien ha sido inevitable que la normativa en esta materia evolucione en un sentido más técnico y especializado, los continuos cambios que ha sufrido el ordenamiento y algunas deficiencias propias de la técnica legislativa, así como la propensión a la sobrerregulación, ha dificultado que la figura del arbitraje en contratación pública pueda consolidarse plenamente como una institución jurídica.

En ese contexto, si bien las últimas modificaciones dadas a la Ley $\mathrm{N} .^{\circ} 30225$ y su Reglamento están orientadas a enfrentar algunos escenarios de reto, como la necesidad de establecer lineamientos para una evaluación más seria y razonable sobre cuán eficiente puede ser para el Estado someter las controversias directamente a un arbitraje o agotar previamente la posibilidad de conciliar, así como la demanda de un nuevo enfoque que propugne la institucionalidad arbitral como regla general en el sistema; el riesgo del cambio normativo continúa siendo un factor contingente para los operadores del sistema. Esto no significa que no existan oportunidades de mejora para el arbitraje que deban ser atendidas normativamente; aun así, resulta imperativo que el ordenamiento vire de enfoque hacia un horizonte de mayor estabilidad y sostenibilidad regulatoria, sin excesos que lidien con la sobrerregulación ni con omisiones que propicien vacíos o lagunas jurídicas que deban ser permanentemente corregidas.

El panorama actual del arbitraje está marcado por importantes incorporaciones normativas, como la obligación del análisis costo/beneficio del arbitraje para el Estado y el fortalecimiento de la institucionalidad en la gestión de los arbitrajes; sin embargo, también está marcado por la necesidad de desburocratizar positivamente la gestión arbitral, establecer esquemas de mayor seguridad jurídica tanto para el Estado como para los contratistas en relación a los regímenes normativos aplicables a los arbitrajes, promover una mayor oferta de servicios arbitrales institucionales en el interior del país, fortalecer la confianza y credibilidad en las instituciones arbitrales, así como mitigar el riesgo latente de la corrupción a través de una mayor cultura arbitral orientada a eliminar la participación de agentes que hacen mal uso o distorsionan algunos atributos del arbitraje. Aún hay mucho camino por recorrer.

\section{REFERENCIAS BIBLIOGRÁFICAS}

Araujo Juárez, J. Los títulos habilitantes en materia de telecomunicaciones en Venezuela. México: Biblioteca Jurídica Virtual del Instituto de Investigaciones Jurídicas de la UNAM. Recuperado de: https://archivos.juridicas.unam.mx/ www/bjv/libros/7/3043/8.pdf

Bazo Reisman, A. (2015). La Ley. Recuperado de http://laley.pe/not/2142/-como-se-aprovechoorellana-de-las-deficiencias-en-la-ley-de-arbitraje-/

Cantuarias Salaverry, F. (2002). Participación del Estado peruano en arbitrajes comerciales. Advocatus (7).

Cantuarias Salaverry, F. (2006). Requisitos para ser árbitro. Revista Peruana de Arbitraje. Núm. 2. Lima: Editora Jurídica Grijley.

Castillo Freyre, M. y Sabroso Minaya, R. (2009). El Arbitraje en la Contratación Pública. Lima: Biblioteca de Arbitraje, Palestra.

Comisión Presidencial de Integridad. (2016). Informe Final «Detener la corrupción, la gran bataIla de este tiempo». Resoluciones Supremas N. ${ }^{\circ}$ 258-2016-PCM y N. ${ }^{\circ}$ 264-2016-PCM. Re- 
cuperado de: http://www.transparencia.org. pe/admin/ckfinder/userfiles/files/Informe\%20 Final\%20mComision\%20Presidencial

Contraloría General de la República. (2015). Estudio sobre el Arbitraje en las Contrataciones Públicas durante el periodo 2003-2013. Lima: Departamento de Estudios de la Gerencia de Estudios y Gestión Pública. Recuperado de: https://doc. contraloria.gob.pe/estudios-especiales/estudio/Estudio-Arbitraje-Online.pdf

Guzmán Barrón, C. y Zúñiga Maraví, R. (2014). Tendencias del arbitraje en contratación pública: análisis de laudos arbitrales. Lima: Centro de Análisis y Resolución de Conflictos, Pontificia Universidad Católica del Perú (PUCP). Recuperado de: https://es.scribd.com/document/255436605/Estudio-de-Laudos-Centrode-AnalisiyResolucion-de-Conflictos-Pucp

Kundmüller Caminiti, F. y Rubio Guerrero, R. (2012). Informe para el Banco Mundial: Participación del Estado en los arbitrajes de contratos públicos en el Perú. Presentado en el Fiduciary Forum, Washington DC, mayo. Recuperado de: https://es.slideshare.net/limaarbitration/ estudio-del-banco-mundial-2011
Latorre Boza, D. (2012). La reciente Ley N. 1563 de Colombia. En: Blog «Políticas Públicas y Gestión de Conflictos», PUCP. Recuperado de: http://blog.pucp.edu.pe/blog/derechopublicoyarbitraje/ 2012/10/15/la-reciente-ley-n1563-de-colombia/

Rodríguez Mejía, M. (2011). Requisitos e impedimentos para ser árbitro en el derecho español. Revista de Derecho Privado, edición N. 20. Madrid.

Reporte CONOSCE (diciembre de 2018). Recuperado de: https://public.tableau.com/profile/ osce.bi\#!/vizhome/InformeMensual-ConsolidadoDiciembre2018/IndicadoresdelMercadoEstatal

Reporte SP/RRSSCPALC/DT N. ${ }^{\circ}$ 2-15 del Sistema Económico Latinoamericano y del Caribe (SELA). «Las compras públicas como herramienta de desarrollo en América Latina y el Caribe». Secretaría Permanente del SELA, Caracas, 2015.

TC Expediente N. ${ }^{\circ}$ 020-2003-Al/TC, Expediente N. ${ }^{\circ}$ 020-2003-Al/TC (Tribunal Constitucional, 17 de mayo de 2004). 